conceptualize the quantitative nature of the "catch-up" process, and to make vivid what is already obvious: undernoruished children are at a disadvantage with adults.

\section{REFERENCES AND NOTES}

1. Amirhakimi, G. H., Samloff, I. M., Bryson, M. F., and Forbes, G. B.: Intestinal lymphangiectasia Metabolic studies. Amer. J. Dis. Child., 117 : 178 (1969).

2. Ashworth, A.: Growth rates in children recovering from proteincalorie malnutrition. Brit. J. Nutr., 23: 835 (1969).

3. Barr, D. C. D., Shmerling, D. H., and Prader, A.: Catch-up growth in malnutrition, studied in celiac disease after institution of gluten-free diet. Pediat. Res., 6: 521 (1972).

4. Falkner, F.: Velocity growth. Pediatrics, 51: 746 (1973).

5. Forbes, G. B.: Mathematical models for the analysis of human growth (Presented at IXth International Congress of Nutrition, Mexico City, September 1972).

6. Forbes, G. B., and Reina, J. C.: Adult lean body mass declines with age: Some longitudinal observations. Metabolism, 19: 653 (1970).

7. Kerr, D., Ashworth, A., Picou, D., Poulter, N., Seakins, A., Spady, D., and Wheeler, E.: Accelerated recovery from infant malnutrition with high caloric feedings. In: L. I. Gardner and P. Amacher: Endocrine Aspects of Malnutrition, pp. 467-486 (Kroc Foundation, Santa Ynez, Calif., 1973).

8. Prader, A., Tanner, J. M., and von Harnack, G. A.: Catch-up growth following illness or starvation: An example of develop- mental canalization in man. J. Pediat., 62: 646 (1963).

9. Tanner, J. M., Whitehouse, R. H., and Takaishi, M.: Standards from birth to maturity for height, weight, height velocity and weight velocity for British children. Arch. Dis. Childhood, 41: 454 (1966).

10. Townes, P. L.: Trypsinogen deficiency disease. J. Pediat., 66: 275 (1965).

11. Waterlow, J. C.: The rate of recovery of malnourished infants in relation to the protein and calorie levels of the diet. J. Trop. Pediat., 7: 16 (1961).

12. Williams, J. P. G., Tanner, J. M., and Hughes, P. C. R.: Catch-up growth in male rats after growth retardation during the suckling period. Pediat. Res., 8: 149 (1974).

13. Williams, J. P. G., Tanner, J. M., and Hughes, P. C. R.: Catch-up growth in female rats after growth retardation during the suckling period: Comparison with males. Pediat. Res., 8: 157 (1974).

14. Wilson, P. N., and Osborn, D. F.: Compensatory growth after undernutrition in mammals and birds. Biol. Rev. Cambridge Phil. Soc., 35: 324 (1960)

15. This statement needs qualification for that time of life, such as early infancy, when certain changes in body composition are normally occurring, yet the magnitude of these normal compositional changes are small in comparison to the body weight changes under consideration here.

16. This research was supported by NICHHD Grant no. 18454.

17. Requests for reprints should be addressed to: G. B. Forbes, M.D., Department of Pediatrics, University of Rochester Medical Center, Rochester, N. Y. 14642 (USA).

18. Accepted for publication July 9, 1974.
Burns

emotional trauma

\title{
Long Range Emotional Sequelae of Burns: Effects on Children and Their Mothers
}

\author{
LOGAN WRIGHT ${ }^{(16)}$ AND ROBERT FULWILER \\ Department of Pediatrics, Oklahoma Children's Memorial Hospital, Oklahoma City, Oklahoma, USA
}

\section{Extract}

Twelve children ranging between 8 and 13 years of age who had been hospitalized for burns, their mothers, 12 control children, and 12 control mothers matched for age, sex, socioeconomic status, and the experience of hospitalization were administered a battery of psychologic tests $1.5-5$ years after the burn accidents. This effort produced few differences between burned children and their matched control children. However, the mothers of burned children were found to be significantly more distressed than their matched controls on 10 of 28 study variables.

\section{Speculation}

It is hypothesized that either burn victims' mothers were disturbed prior to the accident and possibly contributed to it or that the emotional sequelae to burns are more extensive with parents (mothers) than with children. It is suggested that more medical and/or emotionally supportive care be consid- ered for the parents of burn victims, with a particular emphasis on restoring appropriate self and role perceptions. Consideration should also be given to feelings of parental insufficiency and unconscious hostility toward the child.

Several articles in the medical and behavioral literature have dealt with emotional reactions and other sequelae to burns and the resulting disfigurement in children. Most have been intuitive or impressionistic in nature, and very few have utilized even minimally rigorous research methods such as quantifiable measures and/or control groups. Although most authors agree that there is emotional trauma associated with being burned and/or disfigured, the precise nature of what burn victims experience (as compared with the behavioral concomitants of other diseases) remains speculative. In particular doubt is the question of how much of the emotional disturbance is an antecedent rather than a consequence of being burned. The purpose of this investigation was to 
quantify and hopefully add clarity to the nature of emotional concomitants of burns of children upon both the victims and their mothers.

\section{METHODS}

\section{SUBJECTS}

One experimental group consisted of 12 children between 8.5 and 13.1 years of age who had been hospitalized for burns at Children's Hospital of the University of Oklahoma at least 1 year before testing. The 12 mothers of these children comprised a second experimental group. A matched pairs control group of 12 parents and another matched pairs control group of 12 children were obtained. Pairs were matched for age, sex, race, socioeconomic status, and the experience of hospitalization, except for problems such as infections which were felt to be less engendering of (or engendered by) emotional problems.

The injuries of the burned children were from various sources: six from clothes catching fire, one scald, two house fires, one flammable glue, and one of unknown origin. The burns were $2^{\circ}$ and $3^{\circ}$ and ranged from $5 \%$ to $50 \%$ of total body area with an average of $21.83 \%$. The length of time from injury to psychologic testing ranged from $18-60$ months with a mean of 38.58 months. Treatment regimes were normal for physical trauma but there was no psychologic intervention for either children or mothers.

\section{PROCEDURE}

All subjects were administered the Peabody Picture Vocabulary Test (PPVT) (12), the Bradley Self Concept Scale (8), the Rorschach Test (10), and the Draw-a-Person Test (DAP) (3), for person, self, and person of opposite sex. The Rosensweig Picture Frustration Test (PF) (11), was administered to all subjects with the children completing the children's form and the mothers the adult form. The Children's Manifest Anxiety Scale (CMAS) (1) was administered to child victims, and the Manifest Anxiety Scale (MAS) (12) to the mothers. The tests were then rated by an experienced clinician who was not aware of the group, experimental or control, to which the subject he was rating belonged. The following variables were rated: CMAS L and A Scales; Rorschach anatomy, content, total number of responses, white space responses, popular responses, and overall level of psychopathology. The results of the DAP's were rated on: raw scorè, distortion of body image, negative effect, and bodily injury. The Rosensweig PF was scored for obstacle dominance, ego defense, need persistence, group conformity rating, extropunitive, intropunitive, and impunitive tendencies.

\section{RESULTS}

Matched-pairs $t$ tests were used to determine statistical differences between experimental and control subjects. There were no differences between experimental and control subjects on chronologic age or PPVT IQ for either children or mothers.

ese data support the adequacy of matching of experimental with control subject.

There were no significant differences between experimental and control children on the CMAS scales, the Rorschach, or the Rosensweig PF study (Table 1). Only 2 of the 31 children's test variables were statistically significant. Both of these variables were from the DAP. The rated age of the person drawn was significant (t 2.85, df $11, P<0.01$ ) as was the negative effect rating ( $\mathrm{t} 2.24$, df $11, P<0.05$ ). The 2 of 31 subtests which were significant do not constitute a number of differences greater than what might be expected by chance.

The 28 variables for mothers, in contrast with those for children, produced 10 significant differences (Table 2). On the
Rorschach, experimental mothers showed more "bad" content responses (t 2.54, df $11, P<0.05$ ), and were rated as having more psychopathology (t 2.70, df $11, P<0.05$ ). The Goodenough raw scores for mothers were significantly different ( $\mathrm{t} 2.14$, df $11, P<0.05$ ) on the "self" drawing, with the experimental group mothers obtaining higher scores. Experimental group mothers also displayed significantly more negative affect ( $\mathrm{t} 3.36$, df $11, P<0.01$ ) in drawings of self. The rated age of person drawings by experimental group mothers was also significantly higher ( $\mathrm{t} 2.39$, df $11, P<0.05)$. On the "opposite sex" drawings of the DAP, experimental group mothers scored higher on age ( $\mathrm{t} 2.15$, df $11, P<0.05)$, and negative affect (t 2.50 , df $11, P<0.05$ ) ratings. This is consistent with their performance on the person drawings. The only difference between mothers on the Rosensweig PF was on the group conformity ratings ( $t 1.80$, df $11, P<0.05$ ), which indicated that experimental group mothers possessed a greater tendency toward bizarre responses than control group mothers.

\section{DISCUSSION}

The data from this study reveal a lack of differences between experimental and control children. Thus, it fails to support previous studies which emphasize either the pre-existence of emotional disturbance or a lasting and dramatically negative emotional impact of burns upon the child victim.

Long and Cope (5) have reported that "significant emotional maladjustment" existed in 9 of 19 burned patients which they studied, although they fail to define "disturbance" or to explain what criteria were employed in measuring it. Martin (7) employed interviews in studying burned children and their parents, but also relied upon nonspecific criteria for measuring disturbance. She concluded that 15 of 35 children were "disturbed" before burn injury. Vigliano et al. (13) reported that $27 \%$ of 160 children, who were emotionally involved after being burned, had been disturbed before the accident. Their criterion of preburn disturbance, however, was the mother's opinion.

Concerning the post-treatment emotional reactions, Jackson (4), Long and Cope (5), Woodward and Jackson (15), and Martin (7) have reported that lasting aggression is common in burned children. Vigliano et al. (13) concluded that burned children see the world as "overpowering" and demanding "toughness," while desiring a dependent relation. They also believe that burned children possessed an immature concept of their physical selves. Woodward (14) reported that, in the post-treatment phase, $81 \%$ of 198 children displayed signs of emotional disturbance ( $26 \%$ severe, $41 \%$ moderate, and $14 \%$ slight) based on the mother's opinion.

The finding of numerous differences between experimental and control mothers, suggests either that the victim's mothers were more disturbed to begin with, or that children may respond to their own burns with greater emotional resiliency than their parents. It could be assumed that $1.5-5$ years is sufficient time for a reasonably stable mother to adapt to a burn crisis, and, if she shows signs of disturbance at that point, one is forced to wonder if she were not chronically disturbed before the burn crisis. If so, her disturbance may have in some way contributed to the accident. Nonetheless, the possibility remains that being burned yourself is a more manageable difficulty than having it happen to one of your children. Thus the resulting problems tend to be somewhat transient in the child, but to linger indefinitely in the mother.

Few authors have reported on the pre-injury emotional states of the parents or the general home atmosphere of children with burns. However, Woodward (14) felt there is no statistical relation between "emotional disturbance" and "unfavorable homes." She states that a "higher percentage" of patients do come from very poor (materially) homes. Long and Cope (5) reported that 8 of 19 patients were from 
"emotionally disturbed" family units. Martin (6) attempted to relate antecedent conditions of burns and scalds to conflicts among and within family members but failed to present quantified data to support her hypotheses.

Upon the occurrence of the accident, most researchers reported that the primary parental reaction of parents was fear for the survival of the child, but that this was quickly followed by guilt and general anxiety about the future. Jackson (4) reported that $60 \%$ of the mothers had "upset nerves," and $16 \%$ suffered a "nervous breakdown," which was felt to be related to guilt and loss of "mother image." Martin (7) reported that the mothers' reactions tended to parallel those of the child at admission, and that parents later displayed depression, guilt, and despair. She also stated that early reactions of the fathers were highly dependent upon the quality of the marital relation, but that many of the fathers subsequently withdrew from the ensuing contacts with both the medical staff and their child because of "their unconscious anxiety that the mother's failure to protect the child might somehow extend to them and expose them to injury also."

Concerning the long range effects of a child's burn injury on parents, Randolf et al. (9) reported that parents tend to

Table 1. Performance of experimental and control children on 31 study variables

\begin{tabular}{|c|c|c|c|c|}
\hline Measure & $\mathbf{M}_{\mathbf{E}}$ & $\mathrm{M}_{\mathbf{C}}$ & df & $\mathrm{t}$ \\
\hline Chronological age & 10.72 & 10.80 & & \\
\hline Peabody Picture Vocabulary Test & 85.66 & 95.50 & 11 & -1.62 \\
\hline Bradley Self Concept & 9.25 & 11.83 & 11. & -0.93 \\
\hline \multicolumn{5}{|l|}{ Children's Manifest Anxiety Scale } \\
\hline L scale & 5.25 & 3.33 & 11 & 1.74 \\
\hline A scale & 18.25 & 19.25 & 11 & -0.31 \\
\hline \multicolumn{5}{|l|}{ Rorschach } \\
\hline Anatomy & 0.25 & 0.54 & 11 & -1.64 \\
\hline Bad content & 2.0 & 2.5 & 11 & -0.80 \\
\hline Responses & 22.08 & 20.03 & 11 & 0.35 \\
\hline White space & 3.08 & 4.72 & 11 & -1.24 \\
\hline Popular response & 4.08 & 4.18 & 11 & -0.11 \\
\hline $\mathrm{F}+/$ responses & 0.52 & 0.56 & 11 & -0.77 \\
\hline Pathology & 6.25 & 6.18 & 11 & 0.12 \\
\hline \multicolumn{5}{|l|}{ Draw-a-Person Test } \\
\hline \multicolumn{5}{|l|}{ Self } \\
\hline Goodenough raw score & 20.13 & 22.72 & 11 & -0.76 \\
\hline Distortion & 6.33 & 6.17 & 11 & 0.30 \\
\hline Negative affect & 6.0 & 6.17 & 11 & -0.32 \\
\hline Bodily injury indicators & 0.16 & 0.0 & 11 & 1.00 \\
\hline \multicolumn{5}{|l|}{ Person. } \\
\hline Goodenough raw score & 20.16 & 22.33 & 11 & -0.83 \\
\hline Age & 14.08 & 25.0 & 11 & $-2.85^{\wedge}$ \\
\hline Body injury indicators & 0.08 & 0.16 & 11 & -0.55 \\
\hline Negative affect & 8.25 & 9.42 & 11 & $-2.24^{2}$ \\
\hline \multicolumn{5}{|l|}{ Opposite sex } \\
\hline Goodenough raw score & 19.5 & 22.75 & 11 & -0.94 \\
\hline Age & 17.67 & 20.67 & 11 & -0.55 \\
\hline Body injury indicator & 0.0 & 0.16 & 11 & -1.48 \\
\hline Negative affect & 6.67 & 6.58 & 11 & 0.01 \\
\hline \multicolumn{5}{|l|}{ Rosensweig Picture Frustration } \\
\hline Obstacle dominance & 4.54 & 5.04 & 11 & -0.87 \\
\hline Ego defense & 13.46 & 12.42 & 11 & 1.07 \\
\hline Need persistence & 6.0 & 6.5 & 11 & -0.54 \\
\hline Group conformity rating & 13.63 & 13.79 & 11 & -0.13 \\
\hline Extropunitive & 7.91 & 9.25 & 11 & -0.82 \\
\hline Intropunitive & 5.75 & 5.5 & 11 & 0.36 \\
\hline Impunitive & 10.33 & 9.16 & 11 & 0.81 \\
\hline
\end{tabular}

${ }^{1} P<0.01$

${ }^{2} P<0.05$.
Table 2. Performance of experimental and control mothers on 28 study variables

\begin{tabular}{|c|c|c|c|c|}
\hline Measure & $\mathrm{M}_{\mathrm{E}}$ & $\mathrm{M}_{\mathrm{C}}$ & $\mathrm{df}$ & $\mathrm{t}$ \\
\hline Chronological age & 35.54 & 34.69 & & \\
\hline \multicolumn{5}{|l|}{ Manifest Anxiety Scale Test } \\
\hline L scale & 3.25 & 3.25 & 11 & 0.0 \\
\hline $\mathrm{K}$ scale & 10.67 & 11.42 & 11 & -0.36 \\
\hline A scale & 19.67 & 18.92 & 11 & 0.16 \\
\hline Peabody Picture Vocabulary Test: IQ & 89.17 & 94.42 & 11 & -0.58 \\
\hline \multicolumn{5}{|l|}{ Rorschach } \\
\hline Anatomy & 1.75 & 0.25 & 11 & $2.91^{1}$ \\
\hline Bad content & 5.92 & 0.75 & 11 & $2.77^{1}$ \\
\hline Responses & 15.91 & 12.67 & 11 & 1.44 \\
\hline $\mathrm{Dd}$ & 1.0 & 0.33 & 11 & 1.68 \\
\hline White space & 0.75 & 0.33 & 11 & 1.05 \\
\hline Distress & 6.25 & 3.33 & 11 & $2.70^{2}$ \\
\hline \multicolumn{5}{|l|}{ Draw-a-Person Test } \\
\hline \multicolumn{5}{|l|}{ Self } \\
\hline Goodenough raw score & 23.80 & 18.66 & 11 & $2.14^{2}$ \\
\hline Distortion & 0.30 & 0.22 & 11 & 0.18 \\
\hline Negative Affect & 7.40 & 6.33 & 11 & $3.36^{2}$ \\
\hline \multicolumn{5}{|l|}{ Person } \\
\hline Age & 29.90 & 18.11 & 11 & $2.39^{2}$ \\
\hline Body injury indicators & 0.36 & 0.0 & 11 & $2.61^{2}$ \\
\hline Negative afect & 6.64 & 5.89 & 11 & 1.20 \\
\hline \multicolumn{5}{|l|}{ Opposite sex } \\
\hline Goodenough raw score & 20.64 & 18.40 & 11 & 0.76 \\
\hline Age & 31.82 & 20.40 & 11 & $2.15^{2}$ \\
\hline Body injury indicators & 0.18 & 0.10 & 11 & 1.07 \\
\hline Negative affect & 7.09 & 6.0 & 11 & $2.50^{2}$ \\
\hline \multicolumn{5}{|l|}{ Rosensweig Picture Frustration } \\
\hline Obstacle dominance & 5.25 & 6.65 & 11 & -1.60 \\
\hline Ego defense & 13.75 & 12.70 & 11 & 1.17 \\
\hline Need persistence & 5.0 & 6.65 & 11 & -.43 \\
\hline Group conformity rating & 9.13 & 10.40 & 11 & $-1.80^{2}$ \\
\hline Extropunitive & 11.12 & 10.15 & 11 & 0.57 \\
\hline Intropunitive & 6.50 & 6.40 & 11 & 0.14 \\
\hline Impunitive & 6.38 & 7.45 & 11 & -0.74 \\
\hline
\end{tabular}

${ }^{1} P<0.01$.

${ }^{2} P<0.05$.

display guilt, shame, and a loss of appropriate role perceptions. Jackson (4) stated that parents possessed "unconscious hostility" toward the burned child. Martin (7) hypothesized that such hostility stems from guilt and alienation, causing parents to fluctuate between rejection and overprotection of the child victim. Woodward and Jackson (15) stated that parents are confused, usually unsure about how to handle the child, and often embarrassed about the accident. In one study employing quantifiable data, Vigliano et al. (13) studied the emotional states of the mothers by using two psychiatric interviews, one social worker interview, the Parental Attitude Research Instrument, a questionnaire about the accident, and free drawings of the child before, during, and after the accident. They concluded that 4 of 10 mothers had marital problems ( 2 had been divorced within 1 year of the accident), 7 of 10 were depressed, and that most felt it was necessary to suppress these feelings in order to help the child.

The present study supports the conclusion of Randolf $e t$ al. (9) that parents of burned children experienced a loss of appropriate perceptions, in that experimental group mothers displayed a poorer self-concept as rated from figure drawings. The conclusion of Jackson (4) and Martin (7) that parents of burned children have "unconscious hostility" toward the child due to the role perception loss is tentatively supported by the present study in that the Rorschach and DAP results indicate a 
trend toward both anxiety and hostility. The mothers' DAP's also revealed a consistent trend of differences in negative affect and preoccupation with physical injury and/or deformity. This constitutes further support for this tendency, in that the experimental group mothers tended to draw both "older" and more "distorted" figures. This "image distortion" is also displayed by experimental group mothers in the "nonstandard" response tendency on the Rosensweig PF. From this study, one is forced to hypothesize that the majority of emotional sequelae to burns lies with the parents and not the children. Hence, while supportive care should be extended to both children and parents, it is suggested that special emphasis be placed on restoring appropriate self and role perceptions for the parents. Consideration should also be given to feelings of parental insufficiency and unconscious hostility toward the child.

\section{SUMMARY}

Twelve children who had been hospitalized for burns, their mothers, and 12 control children and mothers matched for age, sex, race, socioeconomic status, and the experience of hospitalization were administered a battery of psychologic tests designed to assess emotional disturbance associated with burns. Significant differences between burned children and their controls were found on only 2 of 31 study variables. This did not constitute a number of differences significantly greater than what might be expected by chance. However, the mothers of burned children were found to be significantly more distressed than their matched controls on 10 of 28 variables. These differences suggested that the mothers of burned children possess very low perceptions of themselves in general and of their ability to fulfill the role of a mother in particular. Data also suggested the presence of considerable unconscious hostility from mothers toward their burned children. It was recommended that more consideration be given to medical and/or supportive care for the parents of child burn victims while continuing to provide support to the vistim.

\section{REFERENCES AND NOTES}

1. Castenada, A., McCandless, B., and Palerno, D.: The children's form of the manifest anxiety scale. Child Develop., 27: 317 (1956).

2. Dunn, L. M.: Expanded Manual for the Peabody Picture Vocabulary Test (Circle Pines, Minnesota, American Guidance Service, Inc., 1965).

3. Goodenough, F. L.: Measurement of Intelligence by Drawings. (Harcourt, Brace \& World, New York, 1926).

4. Jackson, D. M.: The burnt child and his family. Proc. Roy Soc. Med., 61: 1085 (1968).

5. Long, T. R., and Cope, O.: Emotional problems of burned children. New Engl. J. Med. 23: 1121 (1961).

6. Martin, H. L.: Antecedents of burns and scalds in children. Brit. Med. J. Psychol., 43: 39 (1970).

7. Martin, H. L.: Parents' and children's reactions to burns and scalds in children. Brit. J. Med. Psychol., 43: 183 (1970).

8. Parsons, L., Peterson, R., and Davids, A.: Children's manifest anxiety scale and self-concept in emotionally disturbed boys in residential treatment. J. Clin. Psychol., 24: 332 (1968).

9. Randolf, et al.

10. Rorschach, H.: Methodick und Ergebnisse eines Wahrnehumngsdiagnostischen Experiments, Ed. 2 (Huber, Bern, 1893). Al references are the English translation by $P$. Lemkau and $B$. Kroneberg, Grune \& Stratton, New York, 1942).

11. Rosenzweig, S., Fleming, E., and Clarke, H.: Revised scoring manual for Rosenzweig Picture Frustration Study. Author, St. Lou is (1947).

12. Taylor, $J$ : A personality scale of manifest anxiety. J. Abn. Soc. Psychol., 48: 285 (1953).

13. Vigliano, A., Hart, W. L., and Singer, F.: Psychiatric sequelae of old burns in children and their parents. Amer. J. Orthopsychiat. 34: 753 (1964).

14. Woodward, J.: Emotional disturbances of burned children. Brit. Med. J., l: 1009 (1959).

15. Woodward, J., and Jackson, D. M.: Emotional reactions in burned children and their mothers. Brit. J. Plast. Surg., 13: 316 (1961)

16. Requests for reprints should be addressed to: L. Wright, Ph.D. Department of Pediatrics, Oklahoma Children's Memorial Hospital, P. O. Box 26901, Oklahoma City, Okla. 73190 (USA).

17. Accepted for publication July $12,1974$. 